\title{
Bolted joints in quasi-unidirectional glass-fibre NCF composite laminates
}

DOI:

10.1016/j.compstruct.2017.05.075

Document Version

Accepted author manuscript

Link to publication record in Manchester Research Explorer

\section{Citation for published version (APA):}

Inal, O., Balikoglu, F., \& Atas, A. (2018). Bolted joints in quasi-unidirectional glass-fibre NCF composite laminates. Composite Structures, 183, 536-544. https://doi.org/10.1016/j.compstruct.2017.05.075

\section{Published in:}

Composite Structures

\section{Citing this paper}

Please note that where the full-text provided on Manchester Research Explorer is the Author Accepted Manuscript or Proof version this may differ from the final Published version. If citing, it is advised that you check and use the publisher's definitive version.

\section{General rights}

Copyright and moral rights for the publications made accessible in the Research Explorer are retained by the authors and/or other copyright owners and it is a condition of accessing publications that users recognise and abide by the legal requirements associated with these rights.

\section{Takedown policy}

If you believe that this document breaches copyright please refer to the University of Manchester's Takedown Procedures [http://man.ac.uk/04Y6Bo] or contact uml.scholarlycommunications@manchester.ac.uk providing relevant details, so we can investigate your claim.

\section{OPEN ACCESS}




\section{Accepted Manuscript}

Bolted joints in quasi-unidirectional glass-fibre NCF composite laminates

Oğuzcan İnal, Fatih Balıkoğlu, Akın Ataş

PII: $\quad$ S0263-8223(17)30348-3

DOI: http://dx.doi.org/10.1016/j.compstruct.2017.05.075

Reference: COST 8585

To appear in:

Composite Structures

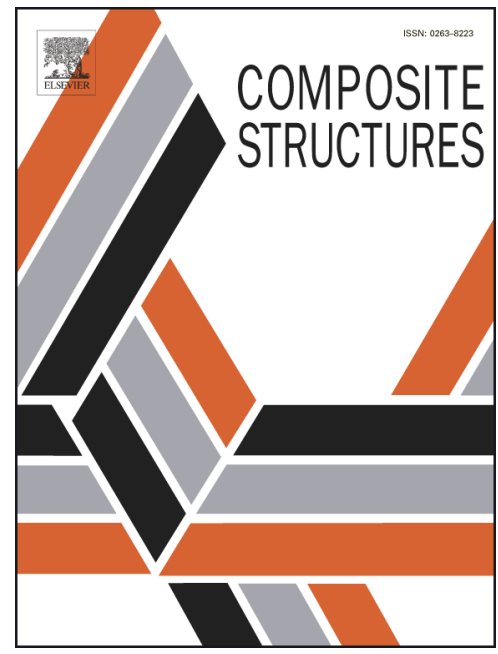

Received Date: $\quad 31$ January 2017

Revised Date: $\quad 4$ April 2017

Accepted Date: $\quad 30$ May 2017

Please cite this article as: İnal, O., Balıkoğlu, F., Ataş, A., Bolted joints in quasi-unidirectional glass-fibre NCF composite laminates, Composite Structures (2017), doi: http://dx.doi.org/10.1016/j.compstruct.2017.05.075

This is a PDF file of an unedited manuscript that has been accepted for publication. As a service to our customers we are providing this early version of the manuscript. The manuscript will undergo copyediting, typesetting, and review of the resulting proof before it is published in its final form. Please note that during the production process errors may be discovered which could affect the content, and all legal disclaimers that apply to the journal pertain. 


\title{
$\underline{\text { Bolted joints in quasi-unidirectional glass-fibre NCF composite laminates }}$
}

\author{
Oğuzcan İnal ${ }^{1 *}$, Fatih Balıkoğlu², Akın Ataş ${ }^{3}$ \\ ${ }^{\mathbf{1}}$ Department of Mechanical Engineering, Balikesir University, Balikesir, 10145, Turkey, inal@balikesir.edu.tr \\ ${ }^{2}$ Department of Mechanical Engineering, Balikesir University, Balikesir, 10145, Turkey, fatih@ balikesir.edu.tr \\ ${ }^{3}$ Department of Mechanical Engineering, Balikesir University, Balikesir, 10145, Turkey, a.atas@balikesir.edu.tr
}

\section{$\underline{\text { ABSTRACT }}$}

In this study, crossply and quasi-isotropic quasi-unidirectional (quasi-UD) non-crimp fabric (NCF) glass/epoxy laminates were manufactured by using vacuum assisted resin transfer moulding (VARTM) and tested according to the ASTM bearing test standard D5961. The specimen geometry was kept constant in all specimens with the ratios of $e / d=3, w / d=6$ for $d=6$ $\mathrm{mm}$. Similar damage modes and damage propagation trends were observed between the classical unidirectional prepreg tapes and the current material system. Furthermore, the bolted joint strength of quasi-UD NCF glass/epoxy laminates was estimated by a three-dimensional (3-D) progressive damage model (PDM) to evaluate the capabilities of a widely used finite element (FE) program, ANSYS. The experimental data and predicted results were in a good agreement and the experimental failure modes were successfully predicted.

Keywords: Non-crimp fabric (NCF) composites, progressive damage modelling (PDM), glass fibre reinforced plastic (GFRP) composites, bolted joint strength.

\footnotetext{
* Corresponding author: inal@balikesir.edu.tr ( Tel: +90 266 6121194/5101), Department of Mechanical Engineering, Balikesir University, Balikesir, 10145, Turkey
} 


\section{Introduction}

Non-crimp fabric (NCF) preforms are one of the most attractive reinforcements for composite materials due to their satisfactory mechanical properties and lower production costs with a wide range of application areas. Although the unidirectional prepreg tapes (UDPT) offer high specific strength and stiffness values they have limited shelf lives and their production costs are relatively higher including autoclave curing procedure. Woven fabrics, on the other hand, offer cheaper production methods but they suffer lower mechanical properties due to the crimp of the interleaved fibres. The NCF composites can overcome certain shortcomings of the UD prepregs and the woven fabrics. While vacuum infusion techniques with low to moderate initial investment cost are well suited for producing the NCF composite laminates, they also provide satisfactory mechanical performance due to less crimped fibres stitched together in order to form the fibre bundles [1-3]. Two well-known structural parts manufactured using the NCF textile reinforcements are the rear pressure bulk head of Airbus A-380 aircraft [4] and Visby Corvette of Swedish Naval Forces. Two major research projects, TECABS [5] and FALCOM [6] were also funded by the European Union given the impact of these material systems on the structural integrity of the contemporary engineering designs.

Drapier and Wisnom [7, 8] were carried out numerical researches based on a 2-D unit cell. First one [7] was aimed to investigate the effect of the crimp on the laminate compressive properties. The FE results were showed that $0^{\circ}$ fiber bundles are the weakest part of the laminates against the meso-buckling. The authors were concluded that the constraint provided by the $90^{\circ}$ fiber bundles might improve the $0^{\circ}$ fiber bundle's stability. The second one [8] was dealt with the inter-laminar shear behaviour. They were concluded that the shear strength is mostly dependent to the mechanical properties of the resin used. Edgren et al. [9] studied the damage progression in cross-ply NCF composites subjected to tensile load. The specimens were loaded until a pre-determined strain level. For the pre-determined strain level the cracks were observed only in $90^{\circ}$ fiber bundles. These cracks were significantly affected Poisson's ratio. However, the longitudinal modulus was not affected because of the undamaged $0^{\circ}$ bundles. Joffe et al. [10] carried out a numerical work considering the effect of the crimp angle on the compressive properties of a NCF composite. The results showed that the failure initiation strain is reducing with the increasing misalignment angle. They also examined the bundle constraint conditions and the support provided by the neighbouring layers to the imperfect bundle was independent from the orientation angle of the neighbouring layer. 
Mattsson et al. [11] studied the effect of the tensile load on $\left[0^{\circ} / 90 \% 0^{\circ} / 90^{\circ}\right]_{\mathrm{s}}$ and $\left[90^{\circ} / 0^{\circ} / 90^{\circ} / 0^{\circ}\right]_{\mathrm{s}} \mathrm{NCF}$ laminates. Even the both laminates suffered $90^{\circ}$ transverse bundle cracks, $\left[0^{\circ} / 90^{\circ} / 0^{\circ} / 90^{\circ}\right]_{\mathrm{s}}$ laminate experienced higher modulus reduction due to delamination at the bundle/matrix interface. The micrograph and FE analyses verified this delamination assumption on the stiffness reduction. Mattsson et al. [12] developed a methodology to characterize the NCF composites with internal structure parameters such as crack types, bundle types, volume fraction calculations and etc. The methodology was based on the optical microscopy observations and was very useful for identification of the laminate quality. A meso-mechanical analysis of the NCF composite based П-joint was carried out by Tserpes and Labeas [13]. A representative volume element (RVE) was introduced with the stitching threads for the homogenization procedure. Hashin criteria [14] was employed for progressive failure analysis and debonding at the interfaces was also included.

On the other hand, when a structural material system is developed, joining alternatives of the system to the metallic or other composite parts should be established and documented according to the in-service loading conditions of particular joints during the lifetime of the structure. Mechanically fastened, bonded and their hybrid combinations are basic joint configurations used in conventional composite structures. Despite the stress concentrations created around the fastener holes, mechanically fastened joints are preferred over the bonded joints mainly due to the simplified maintenance and repair requirements, cheaper installation costs and higher load transferring capacity.

In principal, composite materials give engineers a freedom to tailor the material system and the layer orientations in order to overcome the unique challenges of any structural design. This benefit comes with a cost in terms of variable strength and failure modes especially for the mechanical joint applications. It brings the necessity of robust strength prediction methods that are applicable regardless of the material system and design variables.

Progressive damage modelling (PDM) is a popular strength and damage prediction method for the mechanically fastened joints in composite laminates due to its simplicity and relatively fewer mechanical test requirements for input data. PDM requires the elastic equivalent unidirectional material properties and the strength limits of the material system used. Two main components of a PDM are the damage initiation and material property degradation factors which are determined by the user based on several factors such as the material system used, joint configuration, joint geometry, etc. 
The pre-requisite of any strength prediction method for providing a meaningful result is to input correct material elastic properties and strength data and the PDM is not an exception. Therefore, these input parameters were determined experimentally for the glass fibre NCF composite material system. Another requirement for the PDM is to use damage initiation criteria for different damage modes such as matrix cracks and fibre breakage both in tension and compression peculiar to composite materials. Hashin criteria [14] and maximum stress criterion were used in order to evaluate their performances for the present material system. Hashin and maximum stress criteria were chosen because of their popularity [15-17] and simplicity, respectively. Once the damage onset is predicted, PDM needs degradation factors in order to simulate the effect of the local damage modes on the global response of the structure. Although these factors could be determined by trial and error method for the current material system, they were taken from a previous study [16] due to the logic behind their determination including the physical material behaviour for different damage mechanisms.

Mechanical joints in both unidirectional glass and carbon fibre reinforced composite laminates have been studied extensively since the 1950s. However, new material systems such as the NCF composites may behave in a quite different manner based on their relatively complex fibre architecture. As seen from the previous studies, many researchers were [7-12] focused on the NCF micro-structure which governing the mechanical behaviour. The primary aim of the present paper was to investigate the failure mechanism of bolted joints in glass fibre NCF composite plates and find out their differences in comparison to the well-known UDPT composite laminates. Following the experimental study, PDM was implemented to evaluate its capability on the strength and failure mode determination of the joints.

\section{Experimental Programme}

\subsection{Material system and manufacturing}

A quasi-unidirectional glass non-crimp fabric (Quasi-UD glass NCF) textile preform (Metyx L300E10C) was used as the reinforcement phase of the composite plates. This fabric is specifically called "quasi-unidirectional" instead of cross-ply and/or bi-axial fabrics in the literature [18], since it contains both $0^{\circ}$ and $90^{\circ}$ fibres in the plane of the laminate. The fibre bundles are $1200 \mathrm{Tex}$ and $68 \mathrm{Tex}$ for $0^{\circ}$ and $90^{\circ}$ directions, respectively. The $68 \mathrm{Tex} 90^{\circ}$ bundles (stabilizing bundles) were randomly added in the fabric to achieve better stitching performance and stabilize the $0^{\circ}$ bundles. The images of the quasi-UD NCF textile preform 
with its back and front faces are shown in Fig.1. The details of the textile preform reinforcement including stitch properties are given in Table 1 [19].

Hexion L160 epoxy resin which can be cured at room temperature was used as matrix material with its specific hardener (Hexion H160). Mechanical data of the neat resin is given in Table 2 [20]. Vacuum assisted resin transfer moulding (VARTM) method was used for composite laminate manufacturing. Details of the manufacturing process are given in [21]. After the liquid resin-hardener mixture was vacuumed into the $300 \mathrm{~mm} \times 300 \mathrm{~mm}$ flat mould, the laminate was cured in a vacuum bag under $-700 \mathrm{mmHg}$ pressure for $16-20$ hours. The nominal thickness of an 8-layered composite laminate was $2.5 \mathrm{~mm}$ (thickness of each ply in all specimens was equal to $0.3125 \mathrm{~mm}$ ). The fibre volume fraction of fibre bundles in the laminates was nominally $45 \%$.

Following the curing procedure, the bolt holes were drilled with carbide tipped drills and the bearing specimens were cut into standard sizes with a diamond saw. The fastener hole diameter (d) was equal to $6 \mathrm{~mm}$. The e/d=3 and $\mathrm{w} / \mathrm{d}=6$ ratios were kept constant in all specimens. The clamping torque was selected as $3 \mathrm{Nm}$ according to the related ASTM standard [22]. The geometry of a bearing test specimen is shown in the Fig. 2.

The strengths and elastic properties of the material system, listed in Table 3 and 4 respectively, were obtained with series of coupon tests according to the related ASTM standards [23-25]. These values will be used as inputs in the PDM in Section 3.

Three cross-ply and three quasi-isotropic layups, as listed in Table 5 have been investigated. These layups were taken from our previous studies [26-28], where the material system was HTS40/977-2 carbon fibre/toughened epoxy. Using the same laminate configurations provides an insight into the effect of material system on the mechanical behaviour of the bolted joints for different material systems.

\subsection{Test results}

The specimen preparation procedures and bearing tests were completed according to ASTM D5961 [22]. Tests were conducted at a constant crosshead speed of $2 \mathrm{~mm} / \mathrm{min}$ with a Zwick testing machine and the loading stopped by software embedded into the testing machine when a $30 \%$ load drop was detected. After the tests, the specimens were inspected under the transparent light. Failure load of the specimens was taken as the maximum load sustained 
during the test. Failure load, bearing strength and failure modes are listed in Table 6 . The bearing strength values were calculated according to Eq.1:

$\sigma_{b}=P /(d t)$

where the $P$ is the failure load obtained by the bearing tests, $d$ and $t$ are the hole diameter and the specimen thickness, respectively.

It is clear from the experimental data, the strength results of the cross-ply and quasi-isotropic layups are close to each except for the thinner C-1 layup. It was shown in previous studies [26-28] that the bearing strength of quasi-isotropic laminates in unidirectional carbon fibre reinforced plastic (CFRP) epoxy prepreg laminates was almost 50\% higher than that of the cross-ply laminates for the same geometric parameters used in the present paper $(\mathrm{e} / \mathrm{d}=3$, $\mathrm{w} / \mathrm{d}=6$ and $\mathrm{d}=6 \mathrm{~mm})$. On the other hand, in the cross-ply layups $\mathrm{C}-3$ was remained as strongest and C-1 was remained weakest laminate as in CFRP laminates [26-28]. Likewise, Q-2 was resulted in highest bearing strength and Q-1 was the lowest in the quasi-isotropic layups.

Despite the bearing strength values in comparison to the CFRP laminates, similar failure modes were observed for the current material system; shear-out and bearing mixed mode for the cross-ply and bearing for the quasi-isotropic specimens. Net-tension failure of the whole laminate section was not observed as a result of the high w/d ratio. Shear-out mode was observed only in the cross-ply laminates due to intra-bundle matrix cracks of $0^{\circ}$ layers and inter-laminar delamination between the consecutive $0^{\circ}$ and $90^{\circ}$ layers. The bearing failure mode was observed under the washer area and spread from the edge of the washer to a distance equal to a single bundle width in all layups. In addition, all the specimens with $90^{\circ}$ layers at the outer surfaces (C-1, C-2, C-3 and Q-2) experienced surface bundle separation damage caused by the low strength resin rich areas between the neighbouring fibre bundles. The damage modes observed in C-2 and Q-2 layups were compared for the HTS40/977-2 and current material system with the same geometric parameters. The X-ray images of the carbon UDPT [26] and photographs of the quasi-UD glass NCF/epoxy under transparent light were shown in Figs. 3 and 4.

Representative failure modes are shown in Fig. 5 on an image of a tested C-3 specimen. The dashed outer circle and the hatched inner circle represent the washer edge and the bolt crosssection, respectively. The characters in the Fig. 5 represent; 
a) Intra-bundle matrix cracks of $90^{\circ}$ bundles due to the shear-out of the underlying $0^{\circ}$ plies.

b) Intra-bundle matrix cracks of $90^{\circ}$ bundles

c) Bearing failure under the washer area.

d) Bearing failure extending far equal to one bundle width away from the washer edge.

e) The bundle separation due to the cracking of the resin rich areas between neighbouring fibre bundles.

The cleavage was not observed in any bundle because of the stitching thread which kept the fibres together. The delamination from neighbouring layer and separation of the adjacent bundles in the same layer were occurred at the bundle level.

\section{Progressive Failure Analysis (PFA)}

\subsection{Finite element modelling}

Ansys R14.5 finite element software [29] was implemented for modelling of the bolted joints. SOLID185 elements were used with the reduced integration and full integration formulations for the composite laminate and the bolt/washer assembly, respectively.

In the FE modelling minimizing the data storage space and solution time are as important as obtaining the consistent results. In order to reduce computational time and data storage, a 50 $\mathrm{mm}$ long part of the specimens within the machine grips was not modelled and a mid-plane symmetry condition at the laminate mid-plane was applied to the FE model. One element perlayer approach was used for the composite laminate model. The adjacent layers were assumed to be perfectly bonded and the delamination was neglected between them.

Experimentally determined equivalent linear elastic orthotropic material properties, see Section 2.1, were assigned to the each layer of composite laminate with the fibre orientation of the individual layer. The $0^{\circ}$ layer was assigned to be coincident with the loading direction. The bolt/washer assembly were modelled as steel deformable bodies with material properties of $E=210 \mathrm{GPa}$ and $v=0.3$. Two contact pairs were specified in the bolted joint model. First pair was between washer and laminate, and the second pair was between bolt shank and hole inner wall. All contact surfaces had friction coefficient of 0.2 [30]. 3-D surface-to-surface contact elements, TARGE170 for metal surfaces and CONTA174 for composite surfaces 
were used at the contact surfaces with flexible-to-flexible option. It was assumed that the washer and laminate surfaces will always keep in contact to each other along the through-thethickness direction due to the applied clamping torque. According to this assumption; NO SEPARATION (slide free) option was defined for the contact area between washer and laminate. The contact between hole inner walls and the bolt shank was standard as defined by the contact wizard.

Three specific regions were determined for the mesh structure as shown in Fig.6 (i). Region A where the initial damage was occurred under the washer area, had element size equal to the thickness of a layer (aspect ratio=1). Region B where the damage propagation was observed had the aspect ratio of 3 . Region $\mathrm{C}$ where the damage was not expected to occur 3 had the aspect ratio of 8. The mesh structure of the bolt/washer body is shown in Fig. 6 (ii).

\subsubsection{Boundary conditions}

In order to apply the $3 \mathrm{Nm}$ bolt clamping torque on the composite laminate model the tensile load on the bolt $\left(P_{t}\right)$ was calculated by the following formula [31];

$P_{t}=T /(k d)$

where $k$ is an experimentally determined factor ( 0.2 generally), $d$ is the bolt diameter and $T$ is the applied clamping torque. By solving the Eq. 2 for $3 \mathrm{Nm}$ clamping torque and $6 \mathrm{~mm}$ bolt diameter, the tensile load on the bolt was calculated as $2533 \mathrm{~N}$.

A multistep solution was carried out to apply the clamping torque and the incremental loading on the composite laminate model. In the first step a parametrically determined displacement equal to $0.013 \mathrm{~mm}$ along the negative $\mathrm{Z}$ direction was applied on the surfaces at the mid plane of the bolt shank for simulating the clamping force $(2533 \mathrm{~N})$ on the bolt. In the second step, the incremental displacement was applied on the free edge of the model with a $0.01 \mathrm{~mm} / \mathrm{sub}$ step as determined in Fig. 7 by the preliminary analyses. The outer areas of the bolt/washer assembly were fixed in the $\mathrm{X}$ and $\mathrm{Y}$ directions. The displacement of the bolt/washer assembly through the Z-axis (through-the-thickness) was set free because of the implemented boltpreload in the first sub-step. The boundary conditions of the second step are shown in Fig 8.

\subsection{Progressive damage modelling}

In the development of a PDM, a reference layup is generally chosen for verification of the progressive damage inputs. In this study, C-3 layup was chosen as the reference layup since it 
contains all forms of the observed damage modes. Once, the PDM was verified for the reference layup, later on it implemented to other layups. Following the decision of the reference layup, two progressive damage inputs should be determined by the user; the elastic material property degradation factors and progressive failure initiation criterion. According to the reinforcement construction of the quasi-UD NCF textile including stitching threads and stabilizing fibre bundles, it was assumed that the elements continues to carry some amount of load especially after compressive failure. Therefore, the elastic material degradation factors of Camanho and Matthews [16] listed in Table 7 were selected. These factors were originally introduced by Tan and Perez [32, 33] for open hole compressive loading and were adapted to the bolted joints by Camanho and Matthews [16].

Maximum stress criterion and Hashin criteria [14] were listed in Table 8. These two kinds of criteria were compared for the progressive failure initiation as shown in Fig. 9 for the reference layup. Hashin criteria [14] was failed in the strength prediction due to the low shear strength of the current material system. The shear strength component in the fibre tension, matrix tension and matrix compression damage modes of Hashin Criteria were triggered the early failure and the solution converged before the approximate solution. Also, it was reported by Dano et al. [15], that the large shear stresses occurred at the $45^{\circ}$ angle to the loading direction on the load carrying side of the hole and it may lead the Hashin criteria for inaccurate predictions. Maximum stress criterion was better correlated with the experimental data. The discrepancy of the experimental data and the FE prediction was $4.5 \%$ for the reference layup and the predicted failure modes were consistent with the experiments. Therefore, maximum stress criterion was chosen for the damage onset prediction in all layups.

\subsection{Progressive failure analysis results \& discussions}

The PFA results are listed and compared with the experimental data in Table 9.

Comparison of the failure load values obtained by the PDM showed that the strength prediction of cross-ply laminates was successful with a maximum error of $-5.1 \%$. The lower error was obtained for the cross-ply layups due to the selection of the C-3 layup as reference layup during the model development stage. The failure modes observed in cross-ply laminates were correctly simulated. The propagation of the matrix cracks and the fibre fracture have been demonstrated for the mid-plane $0^{\circ}$ ply of $\left[90^{\circ} / 0^{\circ}\right]_{2 s}$ laminate in Fig. 10. The red colour depicts the fully damaged areas and the blue colour represents the undamaged areas. It is clear that the propagation of the damage with the increasing 
displacement was successfully captured by the PDM. Due to the symmetry of the cross-ply layups about the loading axis, only the half of the images is shown.

In the PFA of the quasi-isotropic layups, the error level was higher especially in Q-1 and Q-3 layups due to the excessive inter-laminar shear stresses occurred. These shear stresses triggered the consecutive failure of elements. The strength predicted by the PDM for Q-1 and Q-3 layups was \%16.5 higher and \%13.4 lower than the experimental value, respectively. Another reason for the high deviation was the choice of C-3 as reference lay-up. If the model verification would be conducted for a quasi-isotropic specimen, the deviation resulted at the PFA of the quasi-isotropic specimens would be smaller than the current results.

Even though the tested specimens were not homogenous in the micro-structural level [12], the composite layers were assumed as homogenous during the modelling stage. Due to this assumption of homogeneity, the PDM were not able to capture the matrix cracks in an individual fibre bundle or between the adjacent bundles. On the other hand, the matrix cracks were detected at the unloaded side of the hole and the transverse matrix cracks of the $90^{\circ}$ plies were not spread as wide as in experiments which was irrelevant in comparison to experiments. However, a highly damaged zone near the bolt hole at the outer $90^{\circ}$ surface layers of C-1, C2, C-3 and Q-2 layups was captured by the PDM. The red colour depicts that the all predefined failure modes (fibre tensile/compression, matrix tensile/compression) was detected. This zone is corresponding to the largest bundle separation location as shown in Fig. 11.

Because of the relatively high error levels in the strength prediction of quasi-isotropic layups, which was between $-13.4 \%$ and $16.5 \%$, another FE model with an aspect ratio of 4 instead of 3 for the mesh region $\mathrm{B}$ was created. The predicted failure modes with the modified mesh were the same as the previous model predictions, which were consistent with the experimental data. The predicted strength deviation was reduced for the new mesh structure especially for Q1 and Q3 layups. Also, in order to observe the influence of the modified mesh on the reference lay-up, an analysis was carried out for the C3 layup as well and the deviation was increased. The results for the initial and modified mesh structures are given together in Table 10.

\section{Conclusions}

Bolted joint strength of quasi-UD NCF composite plates was experimentally and numerically investigated. The mechanical tests were completed according to related ASTM standards [22- 
25]. The observed failure modes were consistent with UDPT laminates for the same geometric parameters [26-28]. However, the strength difference between the cross-ply and quasi-isotropic laminates was lesser than the UDPT laminates. The strength values of the cross-ply specimens were nominally $20 \%$ lower than the quasi-isotropic ones. This is worth noting that the implementation of cross-ply layups in practical applications is also possible with the NCF material system.

A PDM was developed and the bolted joint strength of the cross-ply and quasi-isotropic layups were predicted. The maximum stress criterion was chosen for the progressive damage initiation and the material property degradation factors were taken from the study of Camanho and Matthews [16]. The damage modes were correctly simulated. When a standard mesh structure was used for all the layups, the maximum deviation of the strength predictions from the experimental data was resulted as $5.1 \%$ and $16.5 \%$ for the cross-ply and quasi-isotropic laminates, respectively. It was also demonstrated that the accuracy of the predictions could be improved by adjusting the modelling and solution parameters. Additionally, Hashin Criteria failed to estimate the strength results. The maximum stress criterion, which is simpler compared to Hashin's, succesfully captured the progressive damage and failure load succesfully.

The PDM used in the current study was based on the elastic equivalent material properties and in-plane strength values of the material system. Although the results were satisfying and the commercially available FE program ANSYS is capable of capturing the damage progression, failure modes and strengths of various cross-ply and quasi-isotropic glass NCF composite laminates. The efficiency and accuracy of the model could be improved by including some important physically observed details such as the sub-critical damage mechanisms, delamination onset and propagation behaviour and material in-homogeneity.

\section{Acknowledgements}

Oğuzcan INAL wishes to acknowledge for the fund provided by the Turkish Higher Council of Education (YÖK) within the Academic Training Programme (ÖYP). This study was funded by Scientific Research Projects Department (BAP) of Balıkesir University under the Project BAP.2017.005.

\section{References}


1. Bibo, G., et al., Carbon-fibre non-crimp fabric laminates for cost-effective damagetolerant structures. Composites Science and Technology, 1998. 58(1): p. 129-143.

2. Bibo, G., P. Hogg, and M. Kemp, Mechanical characterisation of glass-and carbonfibre-reinforced composites made with non-crimp fabrics. Composites Science and Technology, 1997. 57(9): p. 1221-1241.

3. Hogg, P.J., A. Ahmadnia, and F.J. Guild, The mechanical properties of non-crimped fabric-based composites. Composites, 1993. 24(5): p. 423-432.

4. Middendorf, P. and C. Metzner, Aerospace applications of non-crimp fabric composites. Non-Crimp Fabric Composites-Manufacturing, Properties and Applications, 2011: p. 441-448.

5. Lomov, S. "TECABS: Technologies for Carbon fibre reinforced modular Automotive Body Structures" $2004 \quad$ 17.12.2016]; Available from: https://www.mtm.kuleuven.be/Onderzoek/Composites/projects/finished_projects/TEC ABS_project.

6. McCarty, C. "FALCOM: Fasterner-less Joining Technologies for High Performance Hybrid Composites-Metal Structures". 2015 17.12.2016]; Available from: http://falcom.ie/images/EU_Project_Details.pdf.

7. Drapier, S. and M.R. Wisnom, Finite-element investigation of the compressive strength of non-crimp-fabric-based composites. Composites Science and Technology, 1999. 59(8): p. 1287-1297.

8. Drapier, S. and M.R. Wisnom, A finite-element investigation of the interlaminar shear behaviour of non-crimp-fabric-based composites. Composites Science and Technology, 1999. 59(16): p. 2351-2362.

9. Edgren, F., et al., Formation of damage and its effects on non-crimp fabric reinforced composites loaded in tension. Composites Science and Technology, 2004. 64(5): p. 675-692.

10. Joffe, R., et al., Compressive failure analysis of non-crimp fabric composites with large out-of-plane misalignment of fiber bundles. Composites Part A: Applied Science and Manufacturing, 2005. 36(8): p. 1030-1046.

11. Mattsson, D., R. Joffe, and J. Varna, Damage in NCF composites under tension: effect of layer stacking sequence. Engineering Fracture Mechanics, 2008. 75(9): p. 26662682.

12. Mattsson, D., R. Joffe, and J. Varna, Methodology for characterization of internal structure parameters governing performance in NCF composites. Composites Part B: Engineering, 2007. 38(1): p. 44-57.

13. Tserpes, K. and G. Labeas, Mesomechanical analysis of non-crimp fabric composite structural parts. Composite Structures, 2009. 87(4): p. 358-369.

14. Hashin, Z., Failure criteria for unidirectional fiber composites. Journal of Applied Mechanics, 1980. 47(2): p. 329-334.

15. Dano, M.-L., G. Gendron, and A. Picard, Stress and failure analysis of mechanically fastened joints in composite laminates. Composite Structures, 2000. 50(3): p. 287-296.

16. Camanho, P. and F. Matthews, A progressive damage model for mechanically fastened joints in composite laminates. Journal of Composite Materials, 1999. 33(24): p. 22482280.

17. Tserpes, K., et al., Strength prediction of bolted joints in graphitelepoxy composite laminates. Composites Part B: Engineering, 2002. 33(7): p. 521-529. 
18. Vallons, K., et al., Quasi-UD glass fibre NCF composites for wind energy applications: a review of requirements and existing fatigue data for blade materials. Mechanics \& Industry, 2013. 14(3): p. 175-189.

19. Datasheet for L300E10C. Metyx A.Ş.

20. Datasheet for EPIKOTE Resin MGS ${ }^{\mathrm{TM}}$ LR160 Hexion Inc.

21. İnal, O., Kıvrımsız Cam Elyaf Takviyeli Kompozit Plakalarda Cıvata Bağlantılarının Deneysel ve Nümerik olarak Incelenmesi, in Department of Mechanical Engineering. 2017, Balıkesir University: Balıkesir.

22. ASTM, D 5961/D 5961 M-05 Standard Test Method for Bearing Response of Polymer Matrix Composite Laminates. 2001, ASTM International: West Conshohocken, Pennsylvania, USA.

23. ASTM, D 6641/D 6641 M-09 Standard Test Method for Determining the Compressive Properties of Polymer Matrix Composites Laminates Using a Combined Loading Compression (CLC) Test Fixture. 2009, ASTM International: West Conshohocken, Pennsylvania, USA.

24. ASTM, D 3518/D 3518 M-94 Standard Test Method for In-Plane Shear Response of Polymer Matrix Composite Materials by Tensile Test of $a \pm 45^{\circ}$ Laminate. 2007, ASTM International: West Conshohocken, Pennsylvania, USA.

25. ASTM, D 3039/D 3039 M-00 Standard Test Method for Tensile Properties of Polymer Matrix Composite Materials. 2000, ASTM International: West Conshohocken, Pennsylvania, USA.

26. Ataş, A. and C. Soutis, Subcritical damage mechanisms of bolted joints in CFRP composite laminates. Composites Part B: Engineering, 2013. 54: p. 20-27.

27. Ataş, A. and C. Soutis, Application of cohesive zone elements in damage analysis of composites: Strength prediction of a single-bolted joint in CFRP laminates. International Journal of Non-Linear Mechanics, 2014. 66: p. 96-104.

28. Ataş, A. and C. Soutis, Strength prediction of bolted joints in CFRP composite laminates using cohesive zone elements. Composites Part B: Engineering, 2014. 58: p. 25-34.

29. ANSYS, in Release 14.5.2013.

30. Ireman, T., Three-dimensional stress analysis of bolted single-lap composite joints. Composite structures, 1998. 43(3): p. 195-216.

31. Collings, T., The strength of bolted joints in multi-directional CFRP laminates. Composites, 1977. 8(1): p. 43-55.

32. Tan, S.C. and J. Perez, Progressive failure of laminated composites with a hole under compressive loading. Journal of Reinforced Plastics and Composites, 1993. 12(10): p. 1043-1057.

33. Tan, S.C., A progressive failure model for composite laminates containing openings. Journal of Composite Materials, 1991. 25(5): p. 556-577. 


\section{Figures}

Figure 1. The images of Metyx L300E10C quasi-UD glass-NCF preform. i) front face and ii) back face.

Figure 2. Geometry of a bearing test specimen [22].

Figure 3. Damage in cross-ply specimens at ultimate load. i) $\left[90^{\circ} / 0^{\circ}\right]_{2 \mathrm{~s}}$ HTS40/977-2 carbon UDPT specimen [26]; (a) transverse matrix cracks, (b) axial splitting, (c)delamination, and (d) compressive fibre failure in $0^{\circ}$ layers. ii) C-2 $\left[90^{\circ} / 0^{\circ}\right]_{2 s}$ glass NCF/epoxy specimen; (a) transverse matrix cracks and bundle separation, (b) bearing failure under the washer area, (c) bearing failure extending far equal to one bundle width away from the washer edge and (d) intra-bundle matrix cracks of $90^{\circ}$ bundles due to the shear-out of the underlying $0^{\circ}$ layers.

Figure 4. Damage in quasi-isotropic specimens at ultimate load. i) $\left[90^{\circ} / 45^{\circ} /-45^{\circ} / 0^{\circ}\right]_{\mathrm{s}}$ HTS40/977-2 carbon UDPT specimen [26]; (a) transverse matrix cracks, (b) $0^{\circ}$ axial splits, (c) delamination and (d) $\pm 45^{\circ}$ axial splits. ii) Q-2 $\left[90^{\circ} / 45^{\circ} /-45^{\circ} / 0^{\circ}\right]_{\mathrm{s}}$ glass $\mathrm{NCF} / \mathrm{epoxy}$ specimen; (a) transverse matrix cracks and bundle separation, (b) bearing failure under the washer area and (c) bearing failure extending far equal to one bundle width away from the washer edge.

Figure 5. An image of a tested C-3 specimen.

Figure 6. The mesh structure of the bolted joint composite laminate. i) Mesh regions of the finite element model of composite laminate and ii) mesh structure of the bolt.

Figure 7. Effect of the displacement increment on the failure load predictions for reduced integration formulation.

Figure 8. Boundary conditions of the second step of the solution following the initial clamping force simulation.

Figure 9. Comparison of the Hashin criteria [14] and maximum stress criterion for reference layup.

Figure 10. Propagation of the fibre fracture and matrix cracks at the mid-plane $0^{\circ}$ ply of C-3 specimen.

Figure 11. The location of the largest bundle separation. i) Photograph of a C-3 specimen under transparent light and ii) damaged areas captured by the PDM. 
Figure 1

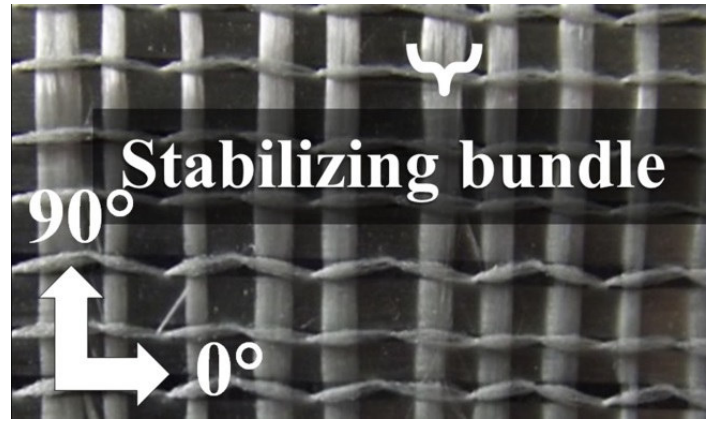

i) Front face

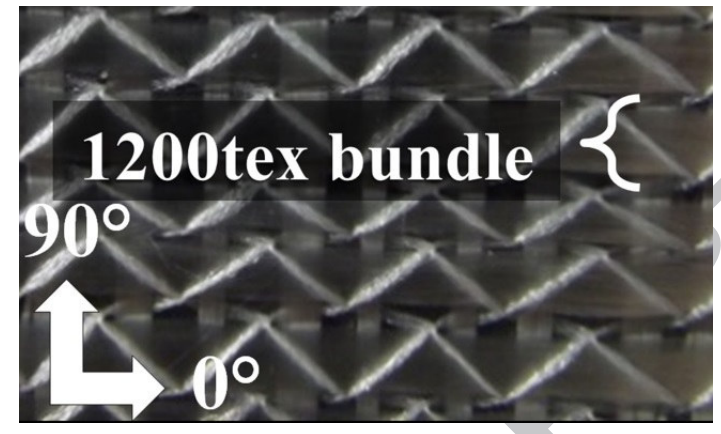

ii) Back face

Figure 2

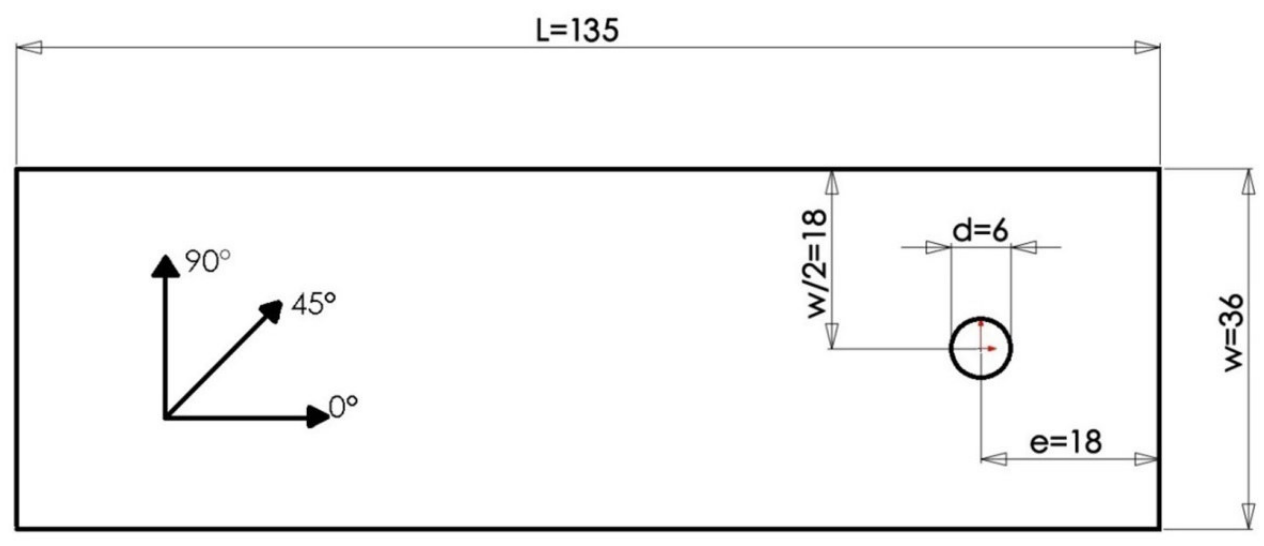


Figure 3

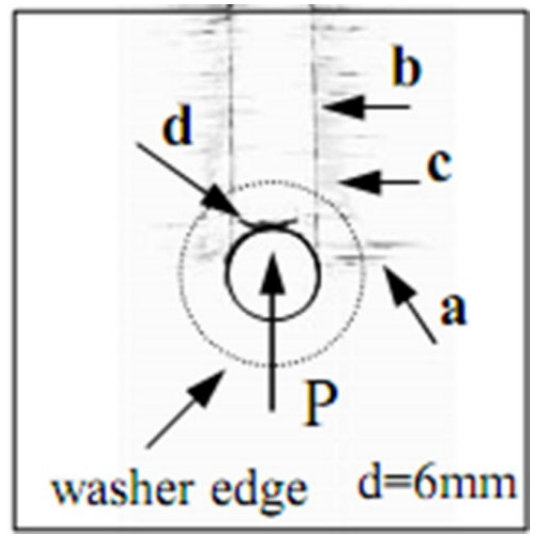

i) $\left[90^{\circ} / 0^{\circ}\right]_{2 s},(\mathrm{w} / \mathrm{d}=6, \mathrm{e} / \mathrm{d}=3)$

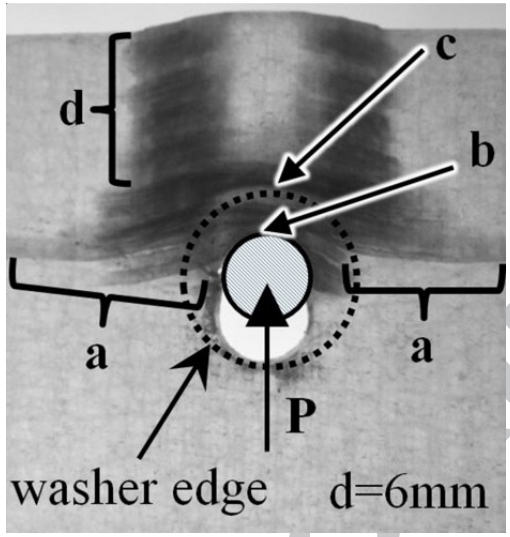

ii) $\mathrm{C}-2\left[90^{\circ} / 0^{\circ}\right]_{2 s},(\mathrm{w} / \mathrm{d}=6, \mathrm{e} / \mathrm{d}=3)$

Figure 4

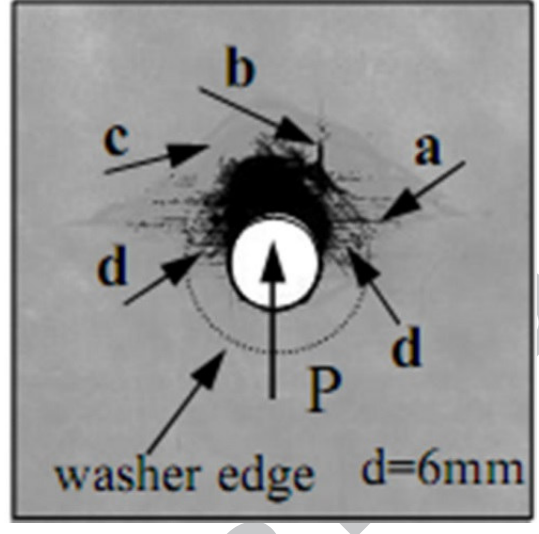

i) $\left[90^{\circ} / 45^{\circ} /-45^{\circ} / 0^{\circ}\right]_{s},(w / d=6, e / d=3)$

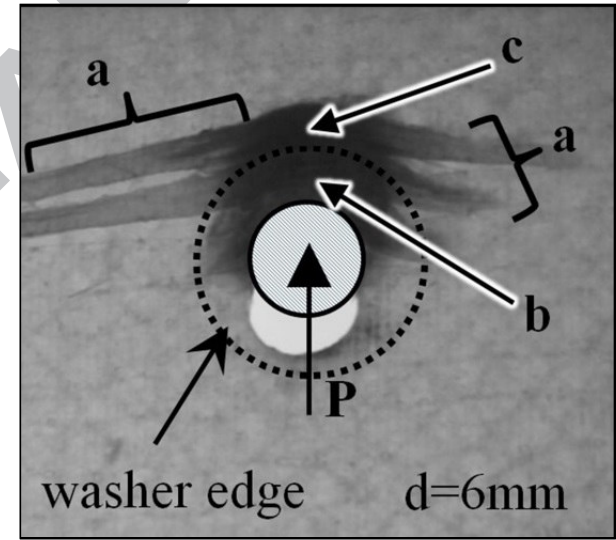

ii) $Q-2\left[90^{\circ} / 45^{\circ} /-45^{\circ} / 0^{\circ}\right]_{s},(w / d=6, e / d=3)$ 


\section{ACCEPTED MANUSCRIPT}

Figure 5

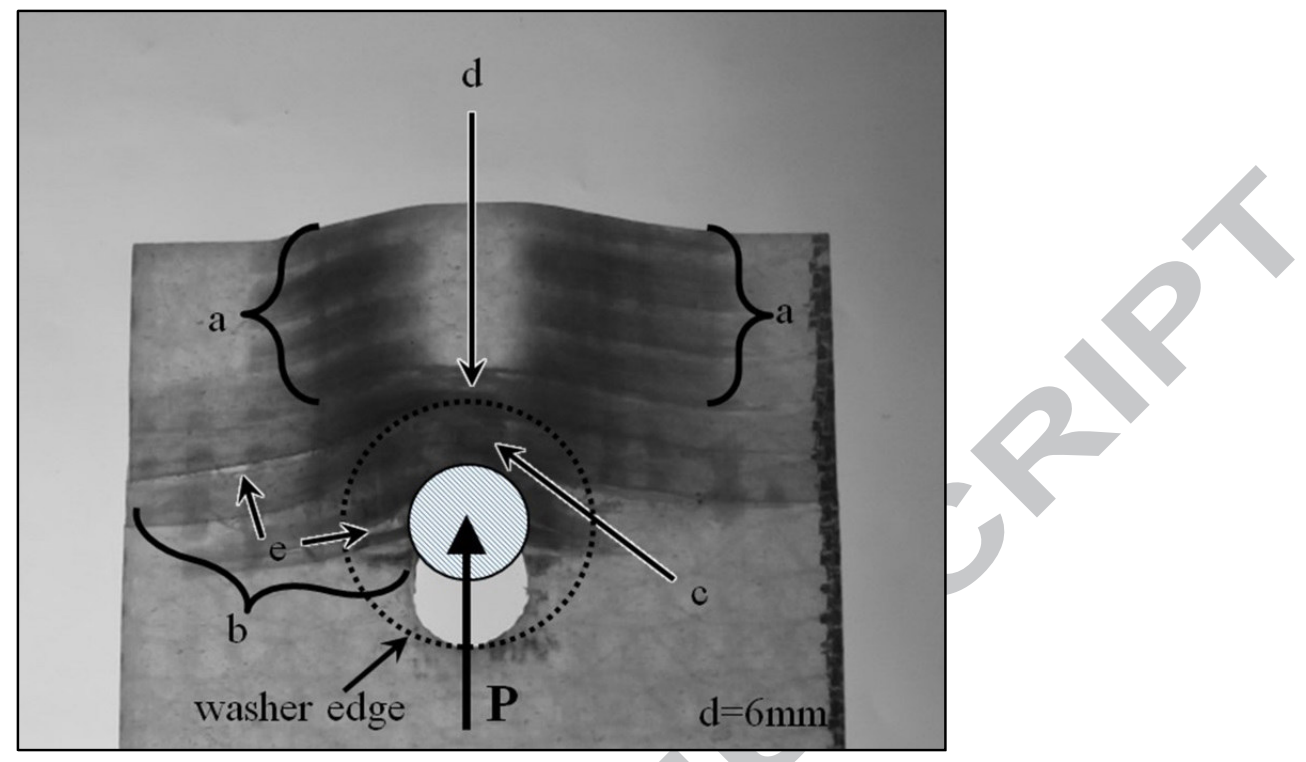

Figure 6

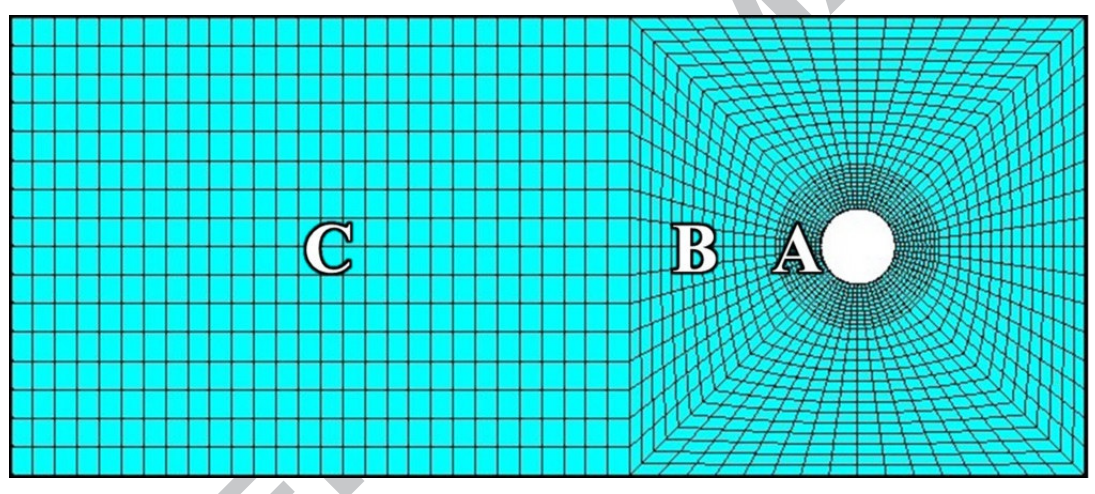

i)

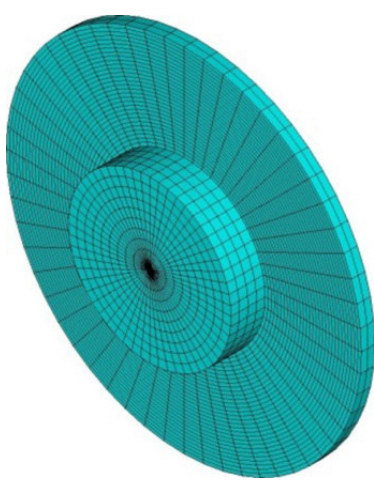

ii) 
Figure 7

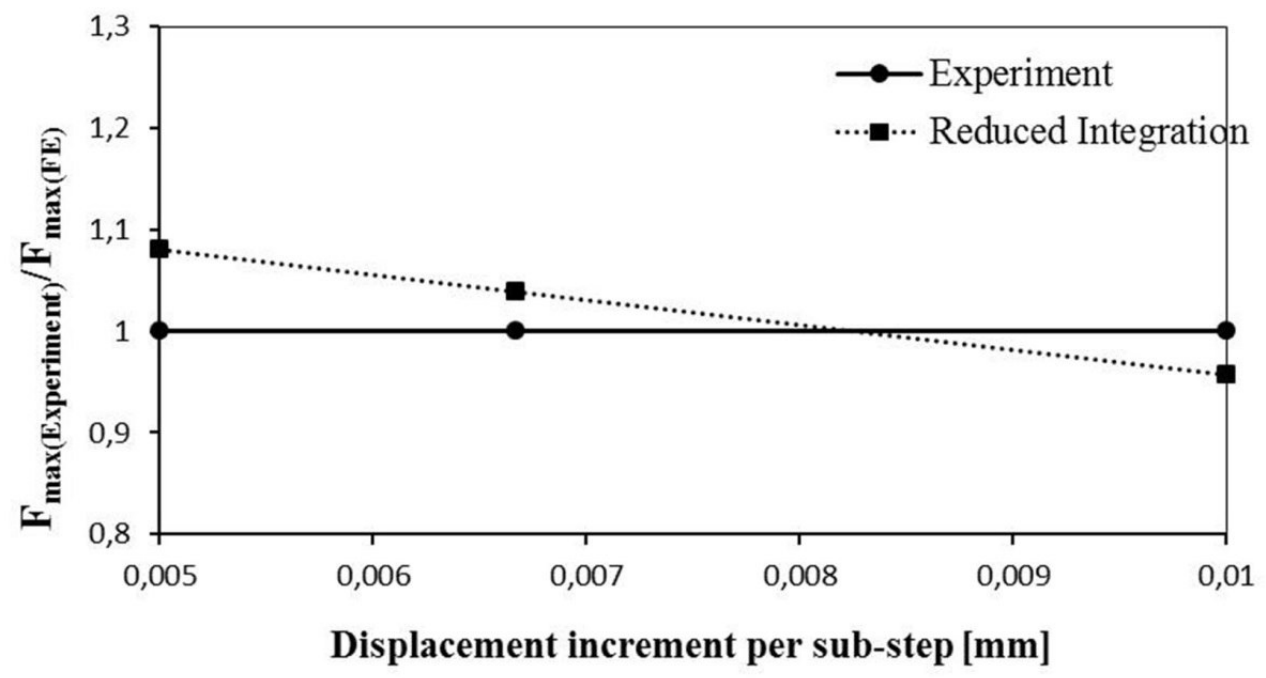

Figure 8

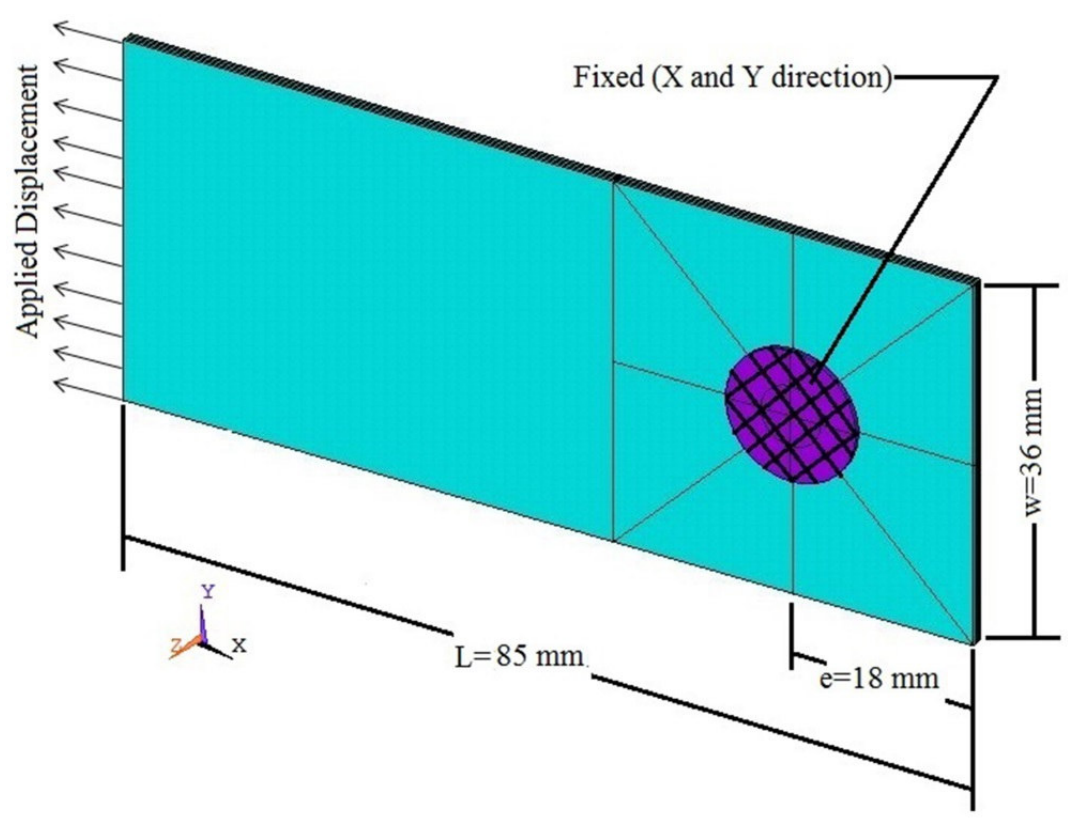


Figure 9

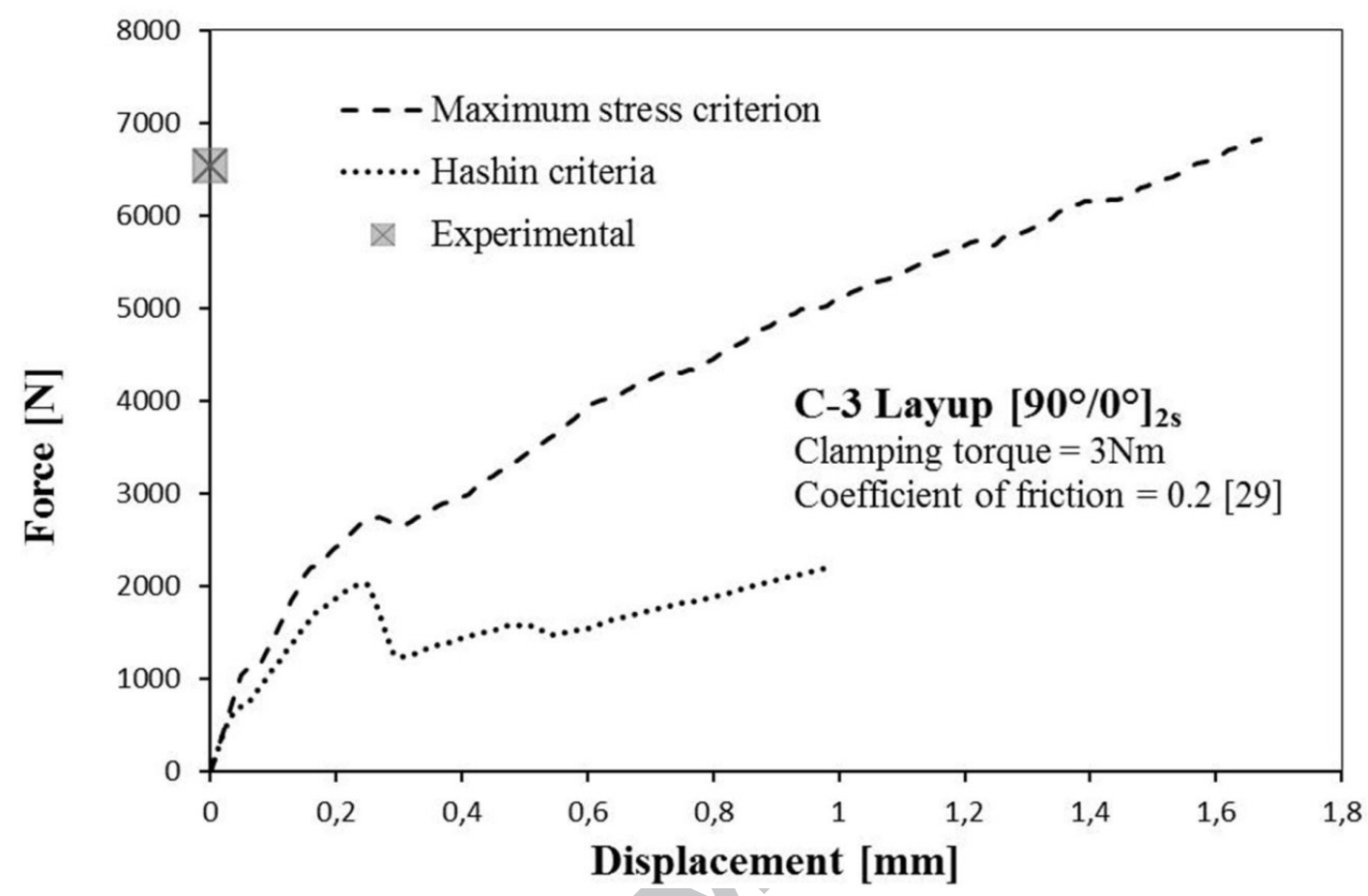




\section{Figure 10}

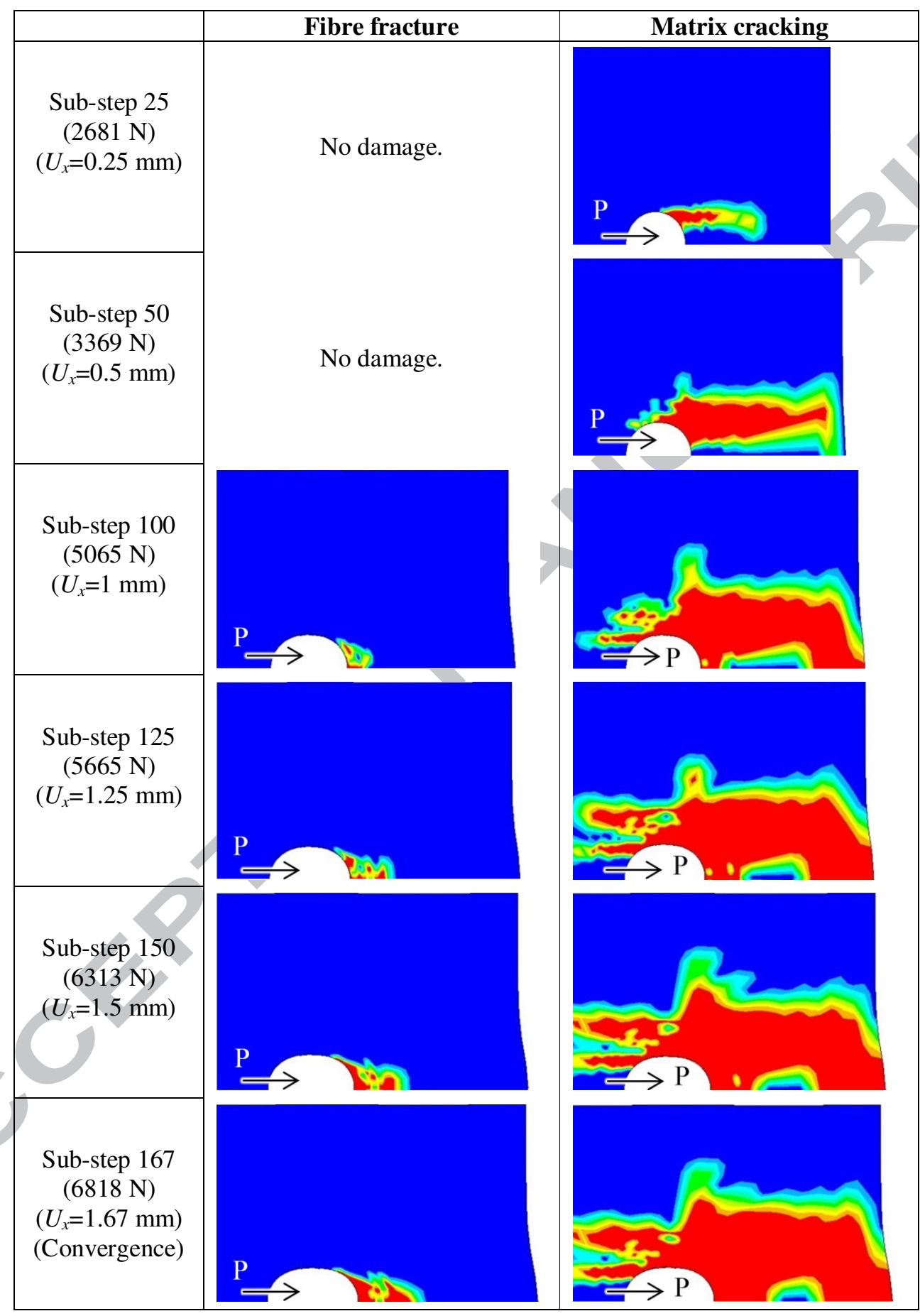


Figure 11

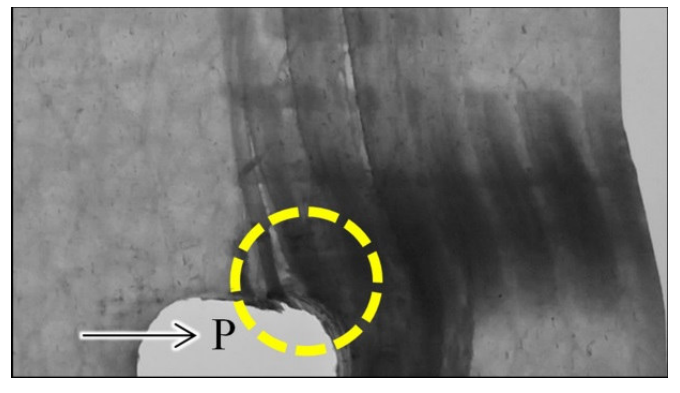

i)

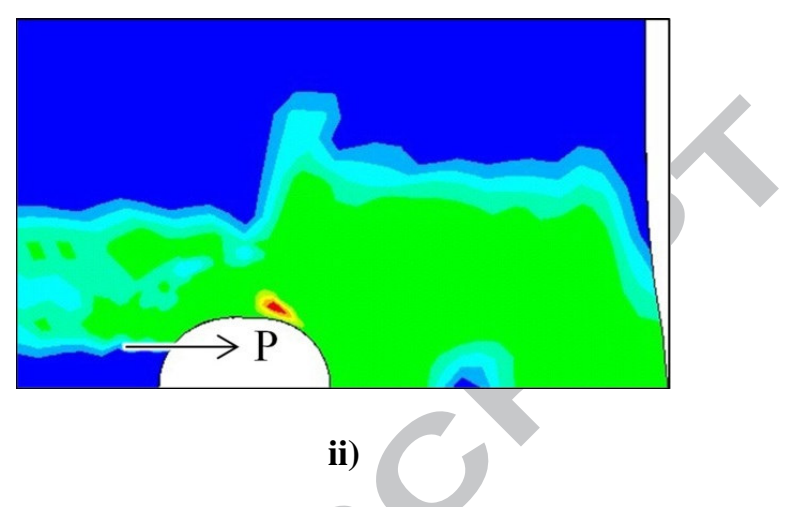


Table 1. Details of the Metyx L300E10C quasi-UD NCF preform [19].

\begin{tabular}{|l|l|c|c|c|}
\hline \multicolumn{2}{|c|}{ Metyx L300E10C } & Layer & Fiber type & Areal weight \\
\hline Stitch Gauge & 10 stitches/inch & $0^{\circ}$ & $1200 \mathrm{Tex}$ & $283 \mathrm{gr} / \mathrm{m}^{2}$ \\
\hline Stitch Type & Tricot & $90^{\circ}$ & $68 \mathrm{Tex}$ & $37 \mathrm{gr} / \mathrm{m}^{2}$ \\
\hline Stitch Length & $3 \mathrm{~mm}$ & Stitch & $76 \mathrm{Dtex}$ & $10 \mathrm{gr} / \mathrm{m}^{2}$ \\
\hline \multirow{2}{*}{} & & Total: & $330 \mathrm{gr} / \mathrm{m}^{2}$ \\
\cline { 3 - 5 }
\end{tabular}

Table 2. Mechanical data of Hexion H160 near resin [20].

\begin{tabular}{|l|c|}
\hline Density $\left(\mathrm{g} / \mathrm{cm}^{3}\right)$ & $1.18-1.20$ \\
\hline Flexural strength (MPa) & $110-140$ \\
\hline Modulus of elasticity (GPa) & $3.2-3.5$ \\
\hline Tensile strength (MPa) & $70-80$ \\
\hline Compressive strength (MPa) & $80-100$ \\
\hline Elongation at break (\%) & $5-6.5$ \\
\hline Poisson's ratio & 0.36 \\
\hline
\end{tabular}

Table 3. Elastic properties of glass NCF/epoxy material system.

\begin{tabular}{c|c|c|c|c|c}
\hline $\mathrm{E}_{11}(\mathrm{GPa})$ & $\mathrm{E}_{22}=\mathrm{E}_{33}(\mathrm{GPa})$ & $\begin{array}{c}\mathrm{G}_{12}=\mathrm{G}_{13} \\
(\mathrm{GPa})\end{array}$ & $\mathrm{G}_{23}(\mathrm{GPa})$ & $v_{12}=v_{13}$ & $v_{23} *$ \\
\hline 28 & 13.2 & 3.9 & 4.85 & 0.22 & 0.36 \\
\hline
\end{tabular}

$* v_{23}$ is taken equal to the epoxy resins Poisson's ratio [19] for the calculation of $G_{23}$ value $\left(G_{23}=E_{22} / 2\left(1+v_{23}\right)\right)$.

Table 4. Strengths of the glass NCF/epoxy material system. 


\begin{tabular}{c|c|c|c|c}
\hline $\mathrm{X}_{\mathrm{T}}(\mathrm{MPa})$ & $\mathrm{X}_{\mathrm{C}}(\mathrm{MPa})$ & $\mathrm{Y}_{\mathrm{T}}=\mathrm{Z}_{\mathrm{T}}(\mathrm{MPa})$ & $\mathrm{Y}_{\mathrm{C}}=\mathrm{Z}_{\mathrm{C}}(\mathrm{MPa})$ & $\mathrm{S}_{\mathrm{XY}}=\mathrm{S}_{\mathrm{XZ}}=\mathrm{S}_{\mathrm{YZ}}(\mathrm{MPa})$ \\
\hline 641 & 421 & 85 & 178 & 35 \\
\hline
\end{tabular}

Table 5. Laminate configurations and codes of the bearing test specimens.

\begin{tabular}{c|c}
\hline Cross-ply specimens & Quasi-isotropic Specimens \\
\hline C-1 $\left[90^{\circ} / 0^{\circ}\right]_{\mathrm{s}}$ & Q-1 $\left[+45^{\circ} / 0^{\circ} /-45^{\circ} / 90^{\circ}\right]_{\mathrm{s}}$ \\
\hline C-2 $\left[90^{\circ}{ }_{2} / 0^{\circ}{ }_{2}\right]_{\mathrm{s}}$ & Q-2 $\left[90 \%+45^{\circ} /-45^{\circ} / 0^{\circ}\right]_{\mathrm{s}}$ \\
\hline C-3 $\left[90^{\circ} / 0^{\circ}\right]_{2 \mathrm{~s}}$ & Q-3 $\left[0 \% / 90 \%+45^{\circ} /-45^{\circ}\right]_{\mathrm{s}}$ \\
\hline
\end{tabular}

Table 6. Bearing test results and failure modes (B: bearing failure, S: shear-out failure)

\begin{tabular}{|c|c|c|c|c|c|c|}
\hline \multirow{3}{*}{ Stacking Sequence } & \multirow{3}{*}{$\begin{array}{l}\text { Failure } \\
\text { Mode }\end{array}$} & \multicolumn{2}{|c|}{ Failure Load (N) } & \multicolumn{2}{|c|}{$\begin{array}{c}\text { Bearing Strength } \\
(\mathrm{MPa})\end{array}$} & \multirow{2}{*}{$\begin{array}{c}\text { Coefficient } \\
\text { of } \\
\text { variance }\end{array}$} \\
\hline & & $\begin{array}{l}\text { Mean } \\
\text { Value }\end{array}$ & Deviation & $\begin{array}{l}\text { Mean } \\
\text { Value }\end{array}$ & Deviation & \\
\hline & & $\mathrm{x}$ & $\mathrm{s}$ & $\mathrm{x}$ & $\mathrm{s}$ & $\mathrm{v}$ \\
\hline $\mathrm{C}-1\left[90^{\circ} / 0^{\circ}\right]_{\mathrm{s}}$ & $\mathrm{B}+\mathrm{S}$ & 2887 & 142.6 & 343 & 17.09 & $4.94 \%$ \\
\hline $\mathrm{C}-2\left[90^{\circ}{ }_{2} / 0^{\circ}{ }_{2}\right]_{\mathrm{s}}$ & $\mathrm{B}+\mathrm{S}$ & 6231 & 98.6 & 415 & 6.57 & $1.58 \%$ \\
\hline $\mathrm{C}-3\left[90^{\circ} / 0^{\circ}\right]_{2 \mathrm{~s}}$ & $\mathrm{~B}+\mathrm{S}$ & 6523 & 373.7 & 434 & 24.91 & $5.72 \%$ \\
\hline Q-1 $\left[+45^{\circ} / 0^{\circ}-45^{\circ} / 90^{\circ}\right]_{\mathrm{s}}$ & B & 6091 & 402.1 & 406 & 26.80 & $6.60 \%$ \\
\hline Q-2 $\left[90^{\circ} /+45^{\circ} /-45^{\circ} / 0^{\circ}\right]_{\mathrm{s}}$ & $\mathrm{B}$ & 7319 & 217.1 & 487 & 14.47 & $2.96 \%$ \\
\hline Q-3 $\left[0^{\circ} / 90^{\circ} / 45^{\circ} /-45^{\circ}\right]_{\mathrm{s}}$ & B & 6926 & 267.4 & 461 & 17.83 & $3.86 \%$ \\
\hline
\end{tabular}

Table 7. Elastic material property degradation rules [16]. 


\begin{tabular}{|c|c|c|c|}
\hline Damage Type & \multicolumn{3}{|c|}{ Degraded Material Properties } \\
\hline Fiber tension $\left(\sigma_{11} \geq 0\right)$ & \multicolumn{3}{|c|}{$E_{11}^{d}=0.07 E_{11}$} \\
\hline Fiber compression $\left(\sigma_{11}<0\right)$ & \multicolumn{3}{|c|}{$E_{11}^{d}=0.14 E_{11}$} \\
\hline Matrix tension or shear $\left(\sigma_{22}+\sigma_{33} \geq 0\right)$ & $E_{22}^{d}=0.2 E_{22}$ & $G_{12}^{d}=0.2 G_{12}$ & $G_{23}^{d}=0.2 G_{23}$ \\
\hline Matrix compression or shear $\left(\sigma_{22}+\sigma_{33}<0\right)$ & $E_{22}^{d}=0.4 E_{22}$ & $G_{12}^{d}=0.4 G_{12}$ & $G_{23}^{d}=0.4 G_{23}$ \\
\hline
\end{tabular}

Note: $d$ indicates the degraded property.

Table 8. Hashin failure criteria [14] and maximum stress criterion.

\begin{tabular}{|c|c|c|}
\hline Failure Mode & Hashin failure criteria & Maximum stress criterion \\
\hline $\begin{array}{l}\text { Matrix tensile } \\
\left(\sigma_{y y}+\sigma_{z z}>0\right)\end{array}$ & $\lambda_{m}^{+}=\left(\frac{\sigma_{y y}+\sigma_{z z}}{Y_{T}}\right)^{2}+\frac{\sigma_{y z}^{2}-\sigma_{y y} \sigma_{z z}}{S_{y z}^{2}}+\frac{\sigma_{x y}^{2}+\sigma_{x z}^{2}}{S_{x y}^{2}}$ & $\lambda_{m}^{+}=\left(\frac{\sigma_{y y}}{V}\right)$ \\
\hline $\begin{array}{c}\text { Matrix } \\
\text { compressive } \\
\left(\sigma_{y y}+\sigma_{z z} \leq 0\right)\end{array}$ & $\begin{array}{r}\lambda_{m}^{-}=\frac{1}{Y_{C}}\left[\left(\frac{Y_{C}}{2 S_{y z}}\right)^{2}-1\right]\left(\sigma_{y y}+\sigma_{z z}\right)+\left(\frac{\sigma_{y y}+\sigma_{z z}}{2 S_{y z}}\right) \\
+\frac{\sigma_{y z}^{2}-\sigma_{y y} \sigma_{z z}}{S_{y z}^{2}}+\frac{\sigma_{x y}^{2}+\sigma_{x z}^{2}}{S_{x y}^{2}}\end{array}$ & $\lambda_{m}^{-}=\left|\frac{\sigma_{y y}}{Y_{C}}\right|$ \\
\hline $\begin{array}{l}\text { Fibre tensile } \\
\qquad\left(\sigma_{x x}>0\right)\end{array}$ & $\lambda_{f}^{+}=\left(\frac{\sigma_{x x}}{X_{T}}\right)^{2}+\frac{\sigma_{x y}^{2}+\sigma_{x z}^{2}}{S_{x y}^{2}}$ & $\lambda_{f}^{+}=\left(\frac{\sigma_{x x}}{X_{T}}\right)$ \\
\hline $\begin{array}{c}\text { Fibre } \\
\text { compressive } \\
\left(\sigma_{x x} \leq 0\right)\end{array}$ & $\lambda_{f}^{-}=\left(\frac{\sigma_{x x}}{X}\right)^{2}$ & $\lambda_{f}^{-}=\left|\frac{\sigma_{x x}}{X_{C}}\right|$ \\
\hline
\end{tabular}

Table 9. The comparison of the PFA results and experimental results.

\begin{tabular}{|l|c|c|c|c|c|}
\hline \multirow{2}{*}{ Stacking Sequence } & \multicolumn{2}{|c|}{ Failure Mode } & \multicolumn{2}{c|}{ Failure Load } & \multirow{2}{*}{ Error (\%) } \\
\cline { 2 - 5 } & Experiment & PFA & Experiment & PFA & \\
\hline $\mathrm{C}-1\left[90^{\circ} / 0^{\circ}\right]_{\mathrm{s}}$ & $\mathrm{B}+\mathrm{S}$ & $\mathrm{B}+\mathrm{S}$ & $2887 \mathrm{~N}$ & $2738 \mathrm{~N}$ & -5.1 \\
\hline $\mathrm{C}-2\left[90^{\circ} / 0^{\circ}{ }_{2}\right]_{\mathrm{s}}$ & $\mathrm{B}+\mathrm{S}$ & $\mathrm{B}+\mathrm{S}$ & $6231 \mathrm{~N}$ & $5962 \mathrm{~N}$ & -4.3 \\
\hline $\mathrm{C}-3\left[90^{\circ} / 0^{\circ}\right]_{2 \mathrm{~s}}$ & $\mathrm{~B}+\mathrm{S}$ & $\mathrm{B}+\mathrm{S}$ & $6523 \mathrm{~N}$ & $6818 \mathrm{~N}$ & 4.5 \\
\hline $\mathrm{Q}-1\left[+45^{\circ} / 0^{\circ} /-45^{\circ} / 90^{\circ}\right]_{\mathrm{s}}$ & $\mathrm{B}$ & $\mathrm{B}$ & $6091 \mathrm{~N}$ & $7294 \mathrm{~N}$ & 16.5 \\
\hline $\mathrm{Q}-2\left[90^{\circ} / 45^{\circ} /-45^{\circ} / 0^{\circ}\right]_{\mathrm{s}}$ & $\mathrm{B}$ & $\mathrm{B}$ & $7319 \mathrm{~N}$ & $7527 \mathrm{~N}$ & 2.8 \\
\hline $\mathrm{Q}-3\left[0^{\circ} / 90^{\circ} / 45^{\circ} /-45^{\circ}\right]_{\mathrm{s}}$ & $\mathrm{B}$ & $\mathrm{B}$ & $6926 \mathrm{~N}$ & $6001 \mathrm{~N}$ & -13.4 \\
\hline
\end{tabular}


Table 10. The comparison of the PFA results and the experimental results with the initial and the modified mesh structures.

\begin{tabular}{|c|c|c|c|c|c|}
\hline \multirow[t]{2}{*}{ Stacking Sequence } & \multirow{2}{*}{$\begin{array}{c}\text { Failure } \\
\text { Load } \\
\text { (Exp.) }\end{array}$} & \multicolumn{2}{|c|}{ Initial Mesh } & Modified & Mesh \\
\hline & & Failure Load & Error $(\%)$ & Failure Load & Error $(\%)$ \\
\hline C-3 $\left[90^{\circ} / 0^{\circ}\right]_{2 \mathrm{~s}}$ & $6523 \mathrm{~N}$ & $6818 \mathrm{~N}$ & 4.5 & $5806 \mathrm{~N}$ & -11 \\
\hline Q-1 $\left[+45^{\circ} / 0^{\circ} /-45^{\circ} / 90^{\circ}\right]_{\mathrm{s}}$ & $6091 \mathrm{~N}$ & $7294 \mathrm{~N}$ & 16.5 & $6285 \mathrm{~N}$ & 3.2 \\
\hline Q-2 $\left[90^{\circ} /+45^{\circ} /-45^{\circ} / 0^{\circ}\right]_{\mathrm{s}}$ & $7319 \mathrm{~N}$ & $7527 \mathrm{~N}$ & 2.8 & $6469 \mathrm{~N}$ & -11 \\
\hline Q-3 $\left[0^{\circ} / 90^{\circ} /+45^{\circ} / 45^{\circ}\right]_{s}$ & $6926 \mathrm{~N}$ & $6001 \mathrm{~N}$ & -13.4 & $6699 \mathrm{~N}$ & 3.2 \\
\hline
\end{tabular}

